\title{
EDITORIAL
}

\section{CREATIVE THINKING AND SOCIAL ENVIRONMENT}

The subject of this issue is quite broad. It considers creativity from the point of view of the sciences, humanities, social studies and cultural studies. Geographically, its authors likewise cover a broad area: Bashkortostan (Russian Federation), Lithuania, Netherlands, Poland, South Korea, Slovenia and Russia. Creativity is the key word which relates every article in this issue. The call to creativity has become increasingly familiar as a catch phrase in artistic activity and creative industry, but they do not have a monopoly on it. Creativity is equally important in social, political and even economic life.

The first part of this issue, "Creativity in Philosophy and in Science", includes answers to such questions as how can philosophy be helpful in creative thinking, how is it possible to formulate new ideas when confronted with new and demanding situations, and which of the dominant perspectives in the philosophy of science - scientific realism, pessimism and instrumentalism - foster scientists' creativity? A consideration of biotechnological immunology combines these viewpoints to highlight some metaphysical challenges.

The second part of this issue is "Creativity in Society and in Social Environments". Success in postindustrial society typically takes on a symbolic form rather than a material form. Social mobility in case of success may be not only vertical but horizontal, too. The social policies meant to transform Shenzhen from a city of industrial mass-production to one of innovation and creativity are mostly aimed at companies and entrepreneurs. Housing for creative talent should be constructed if Shenzen is truly to become attractive as a creative city. The Orthodox Church plays a key role in defining a Belarussian minority's creativity within a multi-ethnic Poland.

This issue "Creative Thinking and Social Environment" attempts to answer the question: How to create spaces in which the specific rules of different academic and non-academic practices of knowledge production can be made visible and negotiable? We have to consider how to forge connections between academics and the creative and artistic researchers who have a tradition of thinking radically "outside the box" in order to make sense of the world. Neo-materialism, for example, tries to explain not only "how discourses come to matter", but also "how matter comes to matter". In our case, the idea of creativity in the sciences, humanities, social and cultural spaces partly answers this question. Building on the idea of the new-materialists, we observe that "past" was never simply there to begin with, and "future" is not what will unfold, but rather "past" and "future" are iteratively reconfigured and enfolded.

Basia Nikiforova 